\title{
AssistlibRAS: Uma Ferramenta de Autoria para a Construção de Sinais da LIBRAS
}

\author{
AssistLIBRAS: An Authoring Tool for Building Signs of LIBRAS
}

\author{
Denys Fellipe Souza Rocha \\ Campus A. C. Simões - Av. Lourival Melo Mota, s/n, \\ Tabuleiro dos Martins, CEP: 57072-900, Maceió -AL. \\ Programa de Pos Graduação (Mestrado) em Informática \\ (PPGI), Insituto de Computação - Universidade Federal de \\ Alagoas (UFAL) \\ contato.denysrocha@gmail.com
}

\author{
Ig Ibert Bittencourt Santana Pinto \\ Campus A. C. Simões - Av. Lourival Melo Mota, s/n, \\ Tabuleiro dos Martins, CEP: 57072-900, Maceió -AL. \\ Programa de Pos Graduação (Mestrado) em Informática \\ (PPGI), Insituto de Computação - Universidade Federal de \\ Alagoas (UFAL) \\ ig.ibert@ic.ufal.br \\ ig.ibert@ic.ufal,
}

\author{
Rafael de Amorim Silva \\ Campus A. C. Simões - Av. Lourival Melo Mota, s/n, \\ Tabuleiro dos Martins, CEP: 57072-900, Maceió -AL. \\ Programa de Pos Graduação (Mestrado) em Informática \\ (PPGI), Insituto de Computação - Universidade Federal de \\ Alagoas (UFAL) \\ $\underline{\text { rafael@ic.ufal.br }}$
}

Resumo Surdo é excluído socialmente por possuir necessidades diferentes, como a de se comunicar. Seu
processo de inclusão se dá por meio da utilização de sua língua nativa, a língua de sinais, no Bra-
sil temos a LIBRAS (Língua Brasileira de Sinais), coberta pela lei no 10.436 de 2002, que torna
seu uso obrigatório como meio de promoção da acessibilidade. Mesmo com o apoio dessa legisla-
ção, o surdo ainda não possui acessibilidade em completude, pois há grande dificuldade na utili-
zação de intérpretes, que não conseguem atender a demanda das organizações e sociedade em ge-
ral. Dessa forma, é prudente fazer o uso adequado das atuais tecnologias, de forma a prover mei-
os de cobrir essa lacuna. Porém, há escassez de tecnologias específicas para esse fim, pois se tra-
ta de uma língua complexa, com gramática e semântica bastante específicas, como por exemplo,
seus parâmetros (configuração de mão, ponto de articulação, expressão facial/corporal, direção e
movimento) que constituem a unidade básica da língua, o sinal. Este trabalho traz a proposta de
uma ferramenta de autoria, onde especialistas podem criar a matéria prima da língua (os sinais),
podendo utilizar esta em alguma outra tecnologia assistiva, como por exemplo: um tradutor, ou
dicionário. O trabalho foi realizado a partir da investigação do problema através do levantamen-
to do atual estado da arte, validação do mesmo com entrevista, caso de uso em forma de testes de
usabilidade, e análise dos resultados obtidos. A ferramenta foi projetada de acordo com as neces-
sidades do usuário final. Como resultados obtidos no caso de uso, os usuários: professora de lín-
gua de sinais e usuário leigo em computação gráfica e língua de sinais construíram quatro sinais,
cada, com escala ascendente de qualidade e comparação com o tempo gasto em cada sinal, ob-
tendo um resultado significante. A avaliação final executada pelo usuário surdo, também mostrou
a eficácia do resultado produzido pelo assistente, através da observação de algumas sentenças
executadas com os sinais produzidos dentro de um tradutor de Português-LIBRAS, relatando seu
grau de compreensão e satisfação.
Palavras-chave: Acessibilidade, AssistLibRAs, Surdo, Língua de Sinais. Palavras-chave: Acessibilidade, AssistLIBRAS, Surdo, Língua de Sinais.

The Deaf is socially excluded because it has different needs, such as to communicate. The process
of inclusion of Deaf people is through the use of their native language, sign language. In Brazil,
we have the LIBRAS (Brazilian Sign Language), covered by Law No. 10.436 of 2002, which makes
its obligatory use as a means of promoting accessibility. Even with the support of this legislation,
the deaf does not have full accessibility, because there is great difficulty in the use of interpreters,
who can not meet the demand of organizations and society in general. Thus, it is prudent to make
proper use of current technologies in order to provide means to cover this gap. However, there are
few specific technologies for this purpose because it is a complex language, with very specific 
grammar and semantics, such as its parameters (hand configuration, pivot point, facial / body language, direction and movement) which constitute the basic unit of language, the sign. This paper presents a proposal for an authoring tool, through which experts can create the raw material of language (the signs) and can use this in some other assistive technology, such as: a translator, or dictionary. The study was conducted based on the investigation of the problem by surveying the current state of the art, validation through interview, case of use in the form of usability testing, and analysis of results. The tool was designed according to the end-user needs. The results were: the sign language teacher and the layperson in computer graphics and sign language built four signals, each with ascending scale of quality and compared to the time spent on each sign, getting a significant result. The final evaluation performed by deaf user also showed the effectiveness of the result produced by the wizard, by observing a few sentences performed with the signals produced in a Portuguese-POUNDS translator, reporting their level of understanding and satisfaction.

Keywords: Accessibility, AssistLIBRAS, Deaf, Sign Language. 



\section{Introdução}

A palavra "Acessibilidade" traduz bem o sentido do que realmente é necessidade, pois tarefas simples como andar, ler ou conversar são triviais para a maioria das pessoas, mas são grandes desafios enfrentados, todos os dias por pessoas que possuem alguma necessidade especial.

Dessa forma, devemos ter um olhar humano, utilizando-se da Tecnologia para propor soluções que venham a sanar tais necessidades. Como defende Radabaugh [1] para as pessoas sem deficiência, a tecnologia torna as coisas fáceis. Para as pessoas com deficiência, a tecnologia torna as coisas possíveis.

O Surdo tem como meio de acessibilidade a utilização de sua língua materna, a língua de sinais, porém vive num país onde a maioria se comunica através de outra modalidade, ou seja, oral-auditiva. Dessa forma, o mesmo acaba sendo excluído socialmente e sendo visto de forma alheia a toda e qualquer situação comum.

Segundo o último censo do IBGE [2] a deficiência auditiva acometia 9,7 milhões de pessoas $(5,1 \%)$ no Brasil, sendo que a deficiência auditiva severa (pessoas com grande dificuldade ou incapazes de ouvir) foi declarada por 2,1 milhões de pessoas, das quais 344,2 mil eram surdas $(0,2 \%)$. Mundialmente são 70 milhões de surdos, $30 \%$ dos surdos brasileiros não sabem ler o Português, os restantes $70 \%$ tem um conhecimento restrito da língua, e especialmente no Estado do Piauí $95 \%$ dos surdos são analfabetos.

Com a lei $n^{\circ} 10.436$ [3], chamada de Lei de LIBRAS, a prática e o acesso à língua de sinais se torna obrigatória nas instituições onde houver algum surdo, cujo artigo $2^{\circ}$ diz: "Deve ser garantido, por parte do poder público em geral e empresas concessionárias de serviços públicos, formas institucionalizadas de apoiar o uso e difusão da Língua Brasileira de Sinais - LIBRAS como meio de comunicação objetiva e de utilização corrente das comunidades surdas do Brasil."

Uma pessoa surda possui necessidades específicas de interação e de inclusão social. Nas escolas atuais, esta pessoa é excluída do direito de aprender, pois tais escolas privilegiam grupos de estudantes que atendem a um padrão de comunicação oral-auditivo, impedindo ou dificultando grupos que utilizem outro tipo de padrão, como a comunicação gesto-visual [4]. Quando essa situação ocorre com o surdo, por exemplo, o mesmo é privado das conversas, explicações e informações. O professor não sabe como lidar, muito menos os colegas de classe, assim o surdo é simplesmente ignorado, e ao fim do ano letivo, o mesmo é posto para a próxima série, criando uma falsa idéia de inclusão social, como retrata Frias e Menezes [4] dizendo que a escola historicamente se caracterizou pela visão da educação que delimita a escolarização como privilégio de alguns grupos, legitimando um processo de exclusão através de suas políticas e práticas educacionais, que reproduzem a ordem social.

Mesmo com o apoio da legislação, o surdo ainda não possui acessibilidade em completude, pois há grande dificuldade na utilização de intérpretes, que não conseguem atender a demanda das organizações e sociedade em geral.

Nesse mesmo contexto, a criação de tecnologias específicas se torna difícil, pois se trata de uma língua complexa, com gramática e semântica diferenciadas, como por exemplo, os parâmetros da língua abordados por Capovilla e Raphael [5] (configuração de mão, ponto de articulação, expressão facial/corporal, direção e movimento) que constituem o sinal, unidade básica da língua, são bastante abstratos e difíceis de serem incorporados a um ambiente computacional, além do alto custo (tempo e recurso) em utilizar tais ambientes não direcionados para este fim.

A proposta deste trabalho é criar e avaliar uma ferramenta de autoria (AssistLIBRAS), onde especialistas podem criar a matéria prima da língua (os sinais), a um custo (tempo e esforço) menor. Dessa forma, os sinais gerados podem ser então incorporados a outra tecnologia assistiva, como por exemplo: um tradutor, ou dicionário.

Segundo Filho et al. [6], ferramentas de autoria são softwares que devem ser operados com facilidade, sem necessitar de profundos conhecimentos de programação, para autores criarem seus próprios conteúdos.

Trazendo para o contexto da criação de sinais, geramos conteúdos digitais. Como retrata Leffa [7]: "Uma Ferramenta de Autoria é um programa de computador usado para a produção de arquivos digitais, geralmente incluindo texto escrito, imagem, som e vídeo".

A pesquisa se dá de forma teórica, experimental e aplicada, pois como primeira fase da proposta, temos a criação da ferramenta, levando em consideração os parâmetros da língua de sinais escolhida, padrão gráfico adotado com o personagem, e um experimento controlado em forma de avaliação de usabilidade da ferramenta.

\section{Embasamento Técnico}

\subsection{Língua Brasileira de Sinais - LIBRAS}

A LIBRAS ou Língua Brasileira de Sinais, materna dos surdos brasileiros foi reconhecida em abril de 2002 com a Lei $n^{\circ} 10.436$ [3], referida como Lei de LIBRAS, cujo artigo primeiro diz: "A LIBRAS é reconhecida como meio legal de comunicação e expressão a Língua Brasileira de Sinais - LIBRAS e outros recursos de expressão a ela associados." 
Há pouco tempo, foi criado o Decreto de Lei 5.626/2005 [8], onde a LIBRAS é regulamentada e são estipuladas algumas normas referentes ao seu uso, com o objetivo de apoiar o processo de comunicação dos surdos brasileiros. Dessa maneira, é de suma importância entender o artigo $3^{\circ}$ do referente decreto que institui a obrigação de todas as licenciaturas terem em seu currículo a LIBRAS como parte do mesmo, como descrito a seguir: "A LIBRAS deve ser inserida como disciplina curricular obrigatória nos cursos de formação de professores para o exercício do magistério, em nível médio e superior, e nos cursos de Fonoaudióloga, de instituições de ensino, públicas e privadas, do sistema federal de ensino e dos sistemas de ensino dos Estados, do Distrito Federal e dos Municípios."

Os acadêmicos comprovam a importância social e pedagógica da LIBRAS. Através de pesquisas em famílias com filhos surdos de pais também surdos, que adotaram rapidamente o uso da LIBRAS dentro de suas casas, percebeu-se que é um enorme benefício e acaba contribuindo para o aprendizado da língua oral (escrita) como sendo segunda língua, e por isso ocorre a socialização da criança. Já nos casos de pais ouvintes, a criança surda não tem contato com a Língua de Sinais em sua casa, por este motivo, seu aprendizado fica limitado à escola, isso faz com que a assimilação de significados se torne ainda mais difícil, tendo em vista que os ouvintes tem contato contínuo com sua língua em todos os âmbitos. De acordo com [9]:

"Crianças surdas, filhos de pais surdos, têm a possibilidade de se desenvolverem num ambiente adequado, no qual o uso de uma língua de sinais supostamente seja efetivo. Este fato demarca a diferença entre as duas realidades, sendo que, filhos surdos de pais ouvintes podem entrar em contato tardiamente com uma linguagem apropriada para seu desenvolvimento."

A língua de sinais é de modalidade gesto-visual, pois se utiliza de movimentos gestuais e expressões faciais que são perceptíveis pela visão, sendo o principal canal na comunicação. Assim, a mesma se diferencia da Língua Portuguesa, de modalidade oral-auditiva, que utiliza como canal de comunicação o som. Também pode-se perceber as diferenças destas línguas dentro de suas estruturas gramaticais.

De acordo com [5], o item básico da LIBRAS, ou seja, os sinais são formados pela combinação de cinco parâmetros observados abaixo:

- Configuração das mãos - configurações feitas com as mãos. Estes formatos podem pertencer ao alfabeto datilológico (alfabeto manual) ou não.

- Ponto de articulação - onde o sinal é feito, podendo tocar o corpo ou estar em um espaço qualquer.
- Expressão corporal e facial - se tratando de uma língua que é totalmente visual, todas as expressões são de extrema importância. Por essas expressões pode-se indicar sentimento, questionamento, entonação, ironia e surpresa.

- Movimento - os sinais podem ser estáticos ou ter movimento.

- Direção - depois feita a configuração com os quatro parâmetros acima, a direção do movimento mostra o sujeito de um verbo.

Para que um sinal seja totalmente compreensível ao surdo, tais parâmetros devem ser empregados corretamente. Vale ressaltar que o parâmetro "expressão facial/corporal" está relacionado à entonação de uma sentença na língua de sinais, que se utilizado de forma incoerente, o sentido da oração é totalmente comprometido.

Tal parâmetro está intimamente ligado à forma de como nos expressamos utilizando a emoção. Segundo Jaques e Viccari [10] entende-se emoção como um grupo de estados afetivos genéricos, onde pode-se encontrar também o humor. Diferente do humor, a emoção se resume a momentos breves, que são voluntários ou involuntários.

Ekman [11] elenca seis emoções básicas que possuem a mesma manifestação facial independente da cultura dos indivíduos que as expressam, como mostrado na Figura 1.

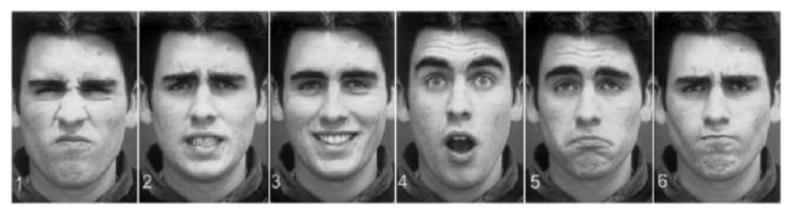

Figura 1: Seis expressões faciais emocionais básicas: (1) repulsa, (2) medo, (3) alegria, (4) surpresa, (5) tristeza e (6) raiva. Schmidt e Cohn [12]

O processo de associação dos sinais aos seus respectivos significados faz com que o surdo identifique suas conceituações, sua identidade em meio ao grupo no qual está inserido. Este surdo possui igual capacidade de aprendizado de um ouvinte, a diferença está no acesso às informações, por isso é comum o processo de defasagem no meio escolar.

Dentro desse contexto é perceptível que a criança surda não consegue acompanhar o aprendizado do restante da turma, pois a metodologia empregada não é inclusiva. $\mathrm{O}$ processo de aprendizagem do surdo é se dá por meios diferentes, como descreve Stumpf [13]: A criança ouvinte, quando vai para a escola, já conhece o significado das palavras. Quando ela aprende a ler, sabe o que as palavras significam, pois o português escrito apresenta características da fala, assim como se fosse um retrato. Quando aprende a ler, a criança ouvinte vê esse retrato e o reconhece. Por outro lado, a criança surda não 
ouve a fala da família. Então, ela vai para a escola, aprende a ler, mas não consegue entender o que as palavras representam, ela não consegue reconhecer o retrato porque antes não ouviu a palavra associada à ação ou ao objeto. Por isso, o surdo parece saber ler mas não entende o significado.

Já se ouviu muito falar sobre o processo de significação da língua de sinais por pessoas ouvintes, estudiosos/pesquisadores. Porém, mais significativo seria ouvir do próprio surdo como ocorre esse processo. Podemos citar a especialista em Pedagogia da Arte (UFRGS) Vales [14], surda, tem como língua natural a LIBRAS, e segunda o Português. "A partir do conhecimento, da apropriação e da utilização da Língua de Sinais, passei a ressignificar minha própria história, compreendo conceitos antes nunca imaginados."

Podemos dizer que hoje a surdez pode ser aceita como fenômeno cultural e não mais como clínico, pois há o conceito de Bilinguismo, respeitando a língua de sinais como sendo a materna do surdo e o português escrito como segunda língua.

Sá [15] ressalta que: A cultura se expressa através da linguagem, dos juízos de valor, da arte, das motivações, etc., gerando a ordem do grupo, com seus códigos próprios, suas formas de organização, de solidariedade, etc. As culturas são recriadas em função de cada grupo que nelas se inserem. Os surdos são um grupo minoritário que estão lutando para que sua cultura seja incluída, no contexto social, como legítima.

A LIBRAS, como qualquer outra língua, possui suas expressões que diferem de região para região, os chamados regionalismos, o que a torna ainda mais legítima como língua. Apesar de ter se originado na França, ganhou independência linguística e possui uma estrutura gramatical própria, incluindo essas variações regionais, como forma de falar, vícios de linguagem, gírias e termos que identificam sua localização.

A luta por esse espaço está presente em todo lugar, mas é partindo da escola que deve acontecer a inclusão social do surdo, trazendo-o para todos os níveis de compreensão e interação com o meio. Essa é uma realidade ainda um pouco distante, como retrata [14] dizendo que os materiais conhecidos pelos professores são restritos ao trabalho com crianças ouvintes, videntes e andantes. $\mathrm{E}$ as crianças surdas, cegas e cadeirantes? Os manuais didáticos empreendem numa visão amplificadora da arte como instrumento de crítica, sensibilidade e criatividade, no entanto restringem suas metodologias a padrões de normalidade.

Portanto, podemos concluir que a LIBRAS vem ganhando espaço, ainda que vagarosamente. Por muito tempo a Língua de Sinais esteve apagada, restrita aos surdos, familiares e escola, mas esse contexto deve se transformar em uma idéia de inclusão total, retirando o surdo das periferias da sociedade e trazendo-o para o centro da comunicação e interação social.

\subsection{Ferramentas de Autoria}

Ferramentas de Autoria permitem que usuários especialistas em um determinado domínio de conhecimento, criarem seus conteúdos de forma a não se preocupar com detalhes técnicos desse processo.

Podemos citar como exemplo, um professor que atua na $\mathrm{EaD}$ (Educação à Distância), onde o mesmo conta com um ambiente preparando com diversos recursos interativos. $\mathrm{O}$ mesmo pode criar um curso, adicionar conteúdos e atividades, como também diversificar a forma de como esses conteúdos são exibidos ao aluno, utilizando textos, vídeos, links, softwares, etc.

Como descreve [16] ferramentas de autoria em elearning (ou AT, para abreviar) permite aos formadores integrar um conjunto de mídias para criar conteúdo de treinamento profissional, envolvente, e interativo, e alguns tornam possível reaproveitar elementos digitalizadas ou objetos de aprendizagem de um curso existente para reutilização em um novo.

Já para [17] ferramentas de autoria são projetados para ajudar o usuário a criar módulos on-line que reúnem todos os componentes de um curso: apresentações de texto, gráficos, links, perguntas e acompanhamento do desempenho dos alunos.

Tais conteúdos descritos acima podem estar em diferentes formatos apresentados ao autor do conteúdo trabalhado, como vídeo, texto, animações, links, etc.

[17] ainda destaca que: elas também permitem que o usuário adicione materiais criados em outros softwares, tais como áudio e vídeo clips, gráficos especializados e animações.

Segundo [16] existem alguns critérios para a escolha da melhor ferramenta de autoria dentro de um determinado contexto, sendo eles:

- Programação automatizada: Ao automatizar a programação para a entrega on-line, ferramentas de criação liberam os desenvolvedores do curso de sua dependência de programadores;

- Interoperabilidade e padrões: a capacidade de uma ferramenta de autoria para trabalhar com outros softwares;

- Tipos de perguntas: Formadores que desenvolvem cursos estão sempre interessados em diferentes tipos de perguntas de avaliação que pode criar com uma ferramenta de autoria;

- Vários caminhos de aprendizagem: para acomodar as diferenças entre os alunos, algumas ferramentas de autoria têm a capacidade de criar variáveis, o que é uma característica importante para a aprendizagem adaptativa;

- Meios de comunicação e arquivo de suporte: A maioria das ferramentas de autoria apoiam tipos de arquivos comuns, como JPGs, WAVs e GIFs, enquanto alguns pacotes suportam streaming de vídeo e áudio.

- Extensibilidade: Alguns treinadores precisam personalizar o software para fins específicos. 
Se você ou sua organização exige alguma personalização para o software de autoria, a certeza de que você tem uma ferramenta com código-fonte aberto, o que permite que um programador de computador especializado para personalizar o software para atender às necessidades do treinador; e

- Custo: A maneira mais eficiente em termos de custo para comprar software de criação é de volume.

Obedecendo a esses critérios, podemos então compreender qual a melhor alternativa para determinado usuário, tendo que este é autor de conteúdo.

Dessa forma, a ferramenta de autoria vem a otimizar o processo de criação de conteúdos, pois seu desenvolvimento é focado nas necessidades do usuário final, onde o mesmo é agente participativo no processo de criação do software, deixando que o autor dos conteúdos não perca tempo com detalhes técnicos, e crie seus materiais com a maior gama de recursos possíveis.

\subsection{Tecnologia utilizada e o processo de animação gráfica}

Após a análise comparativa entre os softwares: Anime Sutdio, Blender e 3D Studio Max, o último foi o escolhido para o desenvolvimento deste trabalho, por ter grande recursividade, ferramentas que possibilitavam a construção da interface AssistLIBRAS. Dessa forma, se mostrou o mais adequado ao objetivo do trabalho.

No ambiente 3Ds Max [18] é possível modelar formas, aplicar texturas, criar cenários através de uma gama de ferramentas. Para o modelador/animador, é mostrado o mesmo objeto de quatro ângulos diferentes, são eles: perspective (perspectiva); front (frente); top (topo) e left (esquerda).

Um outro atrativo bastante interessante e fator decisivo para a utilização de tal software, é que o mesmo possui uma estrutura de ossos pré-definida, o " $b i$ ped", um esqueleto humano onde há todas as restrições de ossos, que quando associado ao personagem modelado, fica bastante natural e de fácil manuseio.

O 3Ds Max abstrai detalhes do usuário, como interpolação de forma e movimento, ou seja, o usuário pode selecionar o membro do personagem e mover para o local desejado, movendo também o marcador da linha de tempo. O programa faz a interpolação de movimento sem mostrar maiores detalhes, desta forma o movimento fica bastante natural e o animador otimiza seu trabalho, como observado na Figura 2.

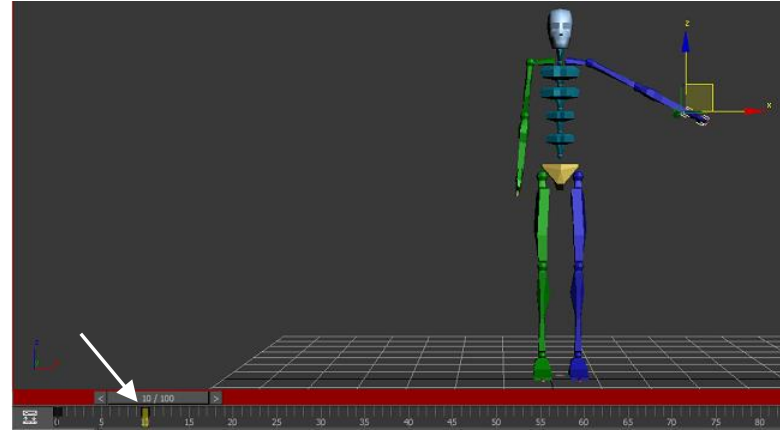

Figura2: Biped animado

A Figura 1 mostra a animação no primeiro frame dentro da linha de tempo, a manipulação do personagem através dos ossos, no caso a mão, e o frame 10 selecionado, mostrando a posição final do movimento.

Desta forma podemos perceber a facilidade de uso do 3Ds Max no processo de animação, o que torna a ferramenta AssistLIBRAS ainda mais intuitiva. Nesta seção, foram mostrados apenas aspectos gerais referentes ao processo de animação no software, há uma infinidade de funções e técnicas que poderiam ser abordadas, mas não contemplariam o escopo deste trabalho.

\section{AssistLIBRAS}

O AssistLIBRAS é uma ferramenta de autoria para a construção de sinais da LIBRAS, direcionado para usuários especialistas na língua, e não é necessário ter nenhum conhecimento mais aprofundado de técnicas de animação gráfica. Algumas das características descritas por Haghshenas et al. estão presentes no AssistLIBRAS, confirmando a classificação deste ambiente. São elas: Programação automatizada, pois o criador dos sinais lida apenas com uma interface de botões e cliques, abstraindo detalhes de toda a programação que está ocorrendo por trás; Interoperabilidade e padrões, ou seja, o produto final é um sinal em forma de vídeo, que pode ser utilizado em outra tecnologia assistiva; Meios de comunicação e arquivos de suporte, pois a ferramenta exporta para vários formatos de imagem (JPEG, PNG, BMP e PSD) e vídeo (AVI, WMV, MPEG e MOV); Extensibilidade, ou seja, a ferramenta pode ser melhorada, pois não há nenhuma forma de bloqueio em sua interface, podendo o usuário personalizar ou acrescentar algum recurso que seja necessário, exemplo: novas expressões faciais; e Custo, pois o assistente é gratuito.

A ferramenta foi construída sob forma de interface projetada no software 3D Studio Max, sendo um arquivo com layout e configurações fixas, próprio para a criação dos sinais. Nele é apresentado um personagem padrão, "Sophya" (personagem feminino) ou "Joe" (personagem masculino), estilo cartoon 3D.

O personagem é visto de três ângulos diferentes, pois na hora da confecção do sinal, o usuário tem uma 
boa visualização espacial do movimento, como visto na Figura 2. O mesmo possui uma estrutura esquelética pré-definida pelo software 3Ds Max, com todas as restrições de movimento humanas.

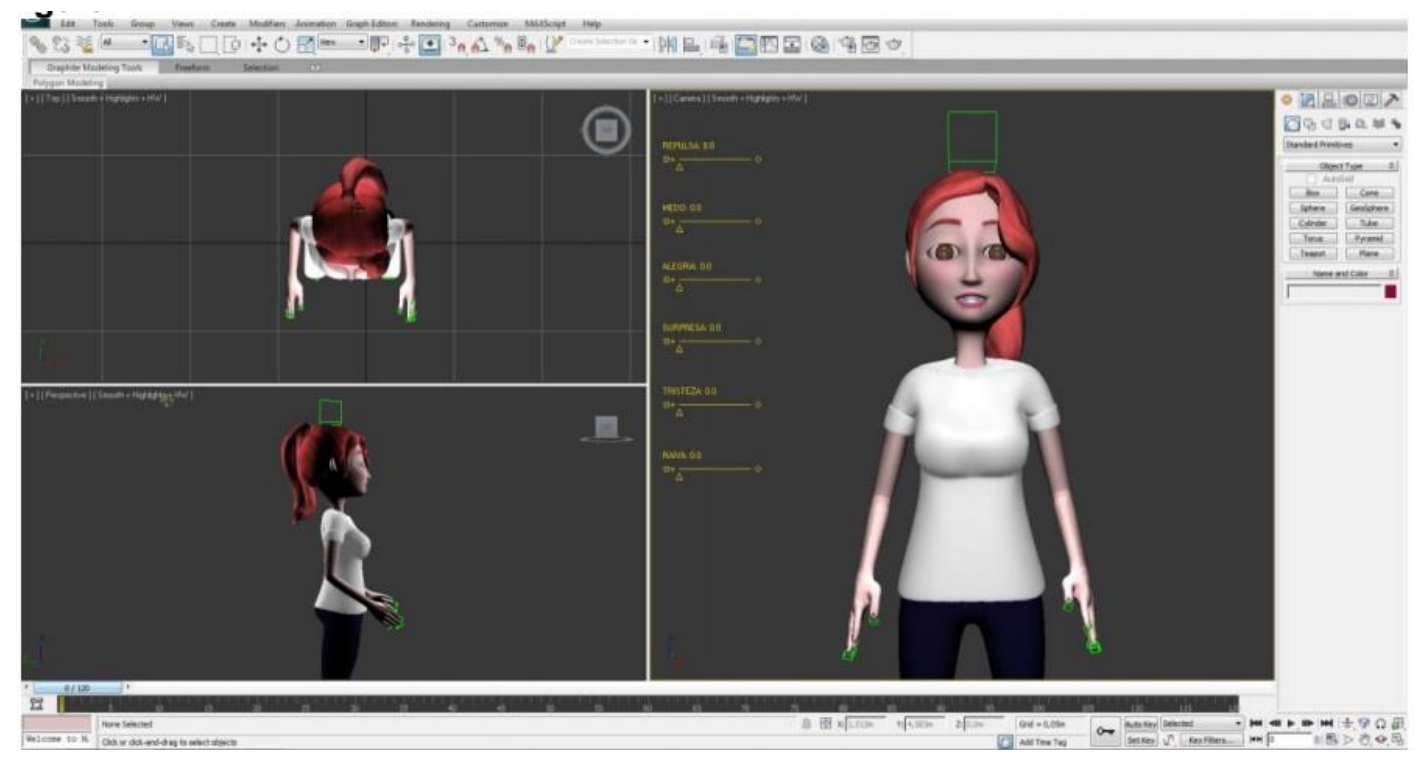

Figura 3: Interface do AssistLIBRAS

No AssistLIBRAS, o usuário deve ter apenas uma breve noção de animação e Time Line (Linha de Tempo), pois é nisto que consiste a criação de cada sinal. Ao final, teremos uma biblioteca robusta, em forma de pequenos vídeos renderizados, que podem ser utilizados em outra tecnologia assistiva, como um tradutor ou dicionário.

Apesar de a ferramenta ter sido projetada para que o processo de criação do sinal se tornasse mais fácil, a qualidade do sinal também depende do manuseio do usuário, pois o mesmo precisa exercitar sua habilidade de animar para que os movimentos produzidos fiquem realmente fiéis ou mais parecidos possíveis aos sinais na vida real, ou seja, naturais.

\subsection{Especificação de Requisitos}

O AssistLIBRAS pode ser considerado um ambiente de geração de atores virtuais articulados, pois nele temos a modelagem de um personagem, que por sua vez pode ser substituído, geração de movimentos com base em uma estrutura composta por restrições, e o resultado final, uma cena renderizada. Como retrata Schneider e Nedel [19]: um sistema capaz de gerar um ator virtual articulado deve considerar quatro etapas: (i) a modelagem do objeto (determinação das articulações e dos graus de liberdade do objeto - uniaxiais, biaxiais ou poliaxiais); (ii) a geração das ações (definição dos gestos necessários para exprimir ideias ou sentimentos); (iii) o carregamento da cena (renderização da cena e manipulação dos dados dos gestos); e (iv) a geração do movimento.
Por ser uma ferramenta característica da IHC (Interação Humano-Computador), as interações se dão através de interfaces, não sendo necessário ter conhecimentos de programação, pois é tudo feito "ao arrastar do mouse". E como mencionado acima, não ficamos presos a "Sophya" ou ao "Joe", pois podemos utilizar outros personagens, e reusar toda a configuração atual, restando como trabalho somente realizar o "rigging", que nada mais é que associar a malha (corpo) ao esqueleto. Esse fator abre possibilidades para a criação de personagens que se adequem a diferentes realidades, ou seja, personagens de varias culturas, sendo aceito em diversos contextos. Não esquecendo que o 3Ds Max também pode guardar o arquivo de animação do esqueleto, gerando uma biblioteca de animações que podem ser utilizados por diferentes personagens, sem que seja necessário recriar tais sinais, mas somente renderizálos, ou seja com o custo de criação ainda menor.

\subsection{Estrutura do Esqueleto}

A estrutura esquelética utilizada no personagem do AssistLIBRAS é o Biped, padrão do 3Ds Max, observado na Figura 4. Nele já temos um esqueleto pronto com todas as restrições humanas, para que os movimentos produzidos não fujam da realidade. 


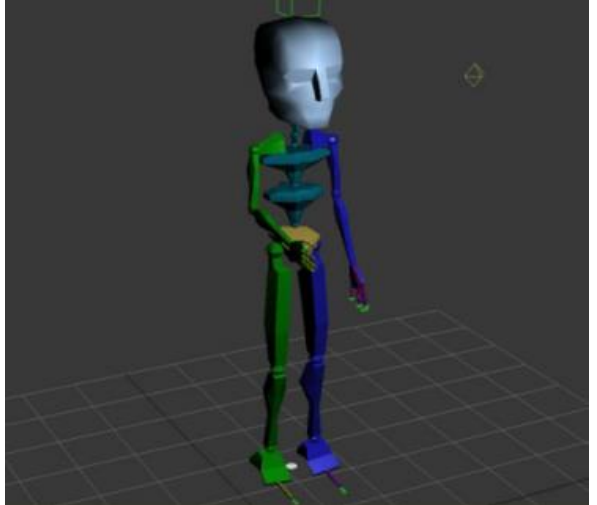

Figura 4: Esqueleto do Personagem

Podemos exemplificar isso de várias formas, utilizando a notação graus. Como por exemplo, quando arrastamos o antebraço para trás do corpo, o mesmo não ultrapassa o ângulo de $180^{\circ}$ em relação ao braço. Isso funciona também com outras restrições de juntas, como joelhos (ângulo de $180^{\circ}$ para frente, canela em relação à coxa) e dedos $\left(180^{\circ}\right.$ para trás em relação a palma da mão). Podemos visualizar esta situação na Figura 5

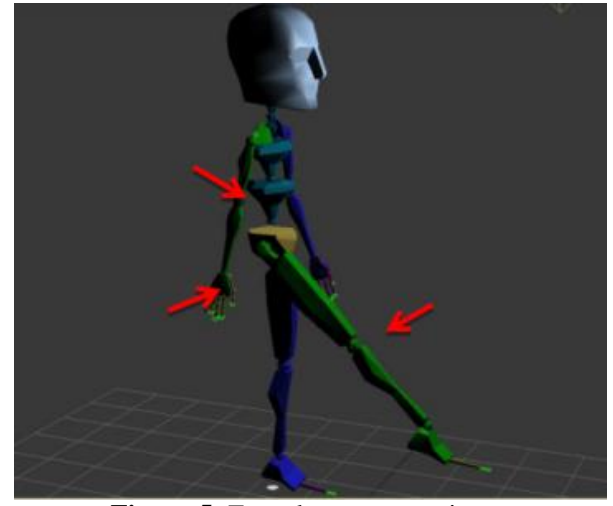

Figura 5: Esqueleto com restrições

Como a animação é feita por interpolação de movimento, e não quadro-a-quadro (frame by fame), só precisamos indicar qual o primeiro e último frame, que o nosso esqueleto faz a interpolação, tornando o movimento natural e de fácil construção.

\subsection{Interface para a geração de sinais}

A ferramenta foi criada para receber uma língua e toda a sua estrutura. Ou seja, temos presente uma interface projetada com os cinco parâmetros da Língua Brasileira de Sinais.

Para criar um sinal temos uma série de passos simples, considerando um processo de animação comum de avatar. Como visto na Figura 6.

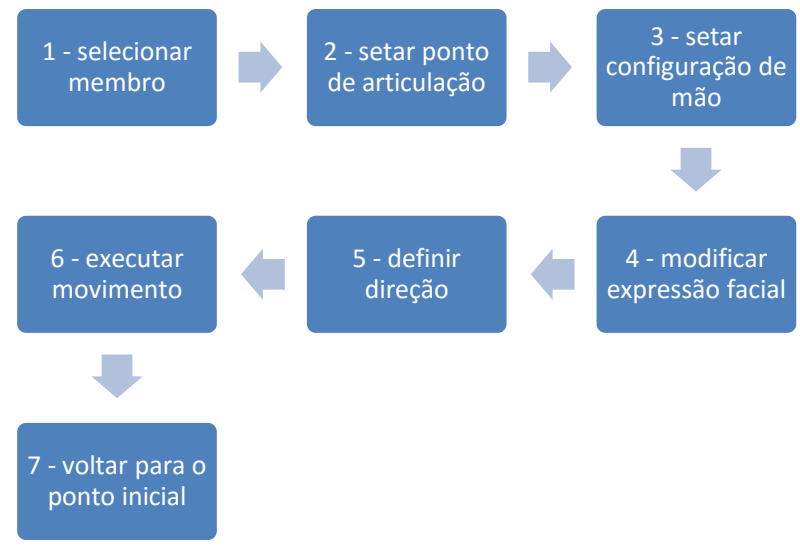

Figura 6: Processo de criação de um sina

O AssistLIBRAS também segue o mesmo processo de criação de sinais, porém quase todos os passos já estão pré configurados, com exceção dos passos 5 definir direção e 6 - executar movimento (Figura 6). Todos os passos do processo apresentado serão mostrados na interface AssistLIBRAS.

1. Primeiro, é preciso selecionar o membro que se deseja mover, através da caixa de seleção, observado na Figura 7.

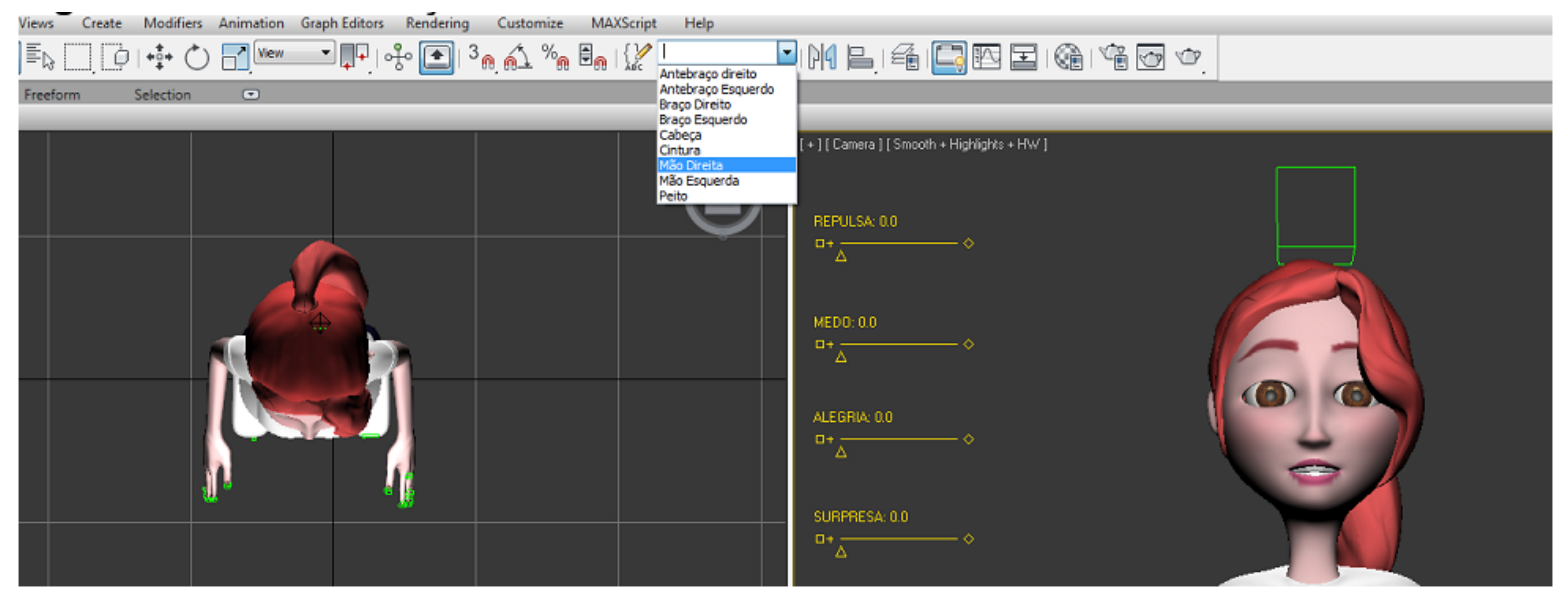

Figura 7: Caixa de seleção 
2. Depois ligamos o botão - Auto Key, para que o 3Ds Max saiba que será gravado um movimento, em seguida clicamos no frame final do referido movimento, selecionamos a ferramenta - Select and Move, e por fim arrastamos o membro selecionado para onde seria o final do movimento, como visto na Figura 8. Com isto caracterizamos dois parâmetros da LIBRAS, o movimento e a direção do sinal.

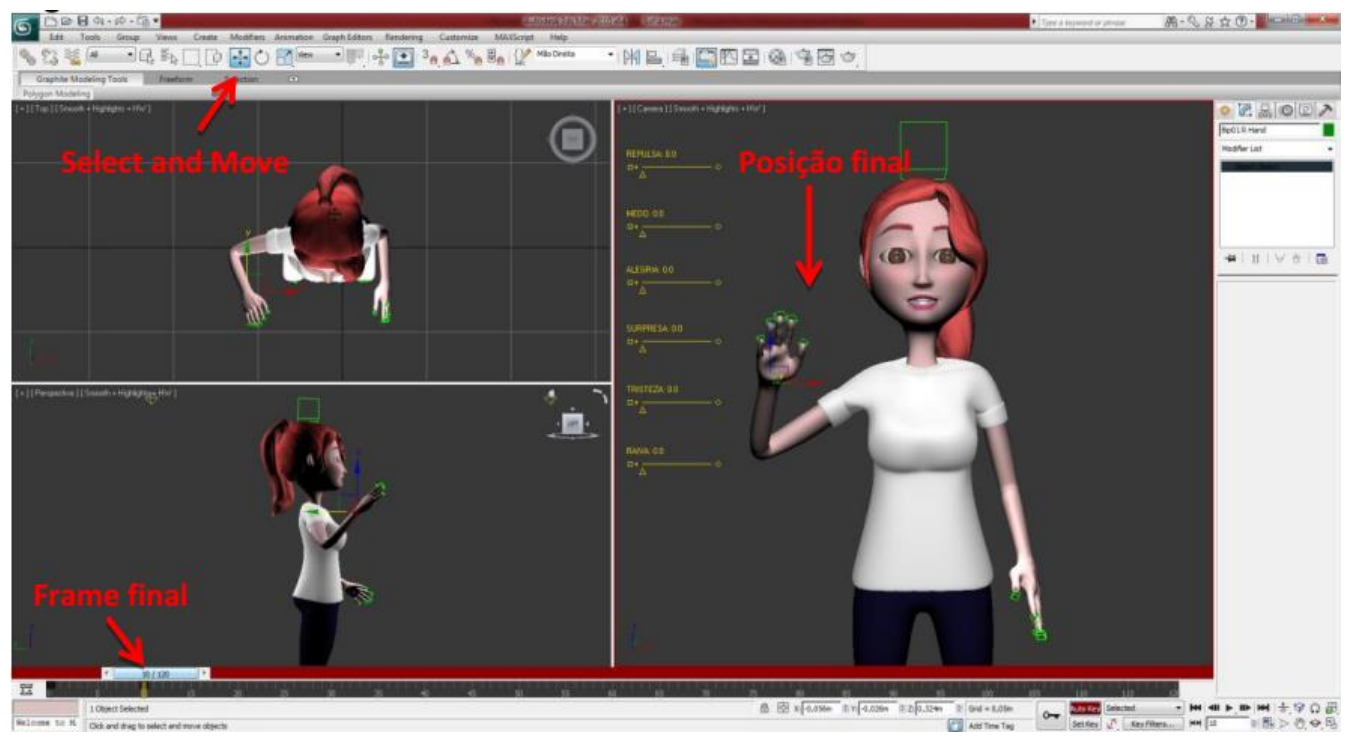

Figura 8: Selecionar e Mover

3. A configuração das mãos é feita através da ferramenta - Copy/Paste, ou seja, temos algumas coleções que indicam qual o tipo da configuração, como por exemplo:

CM_Números,
CM_Símbolos e Ponto_de_Articulação, onde CM quer dizer Configuração da Mão, como demonstrado na Figura 9.
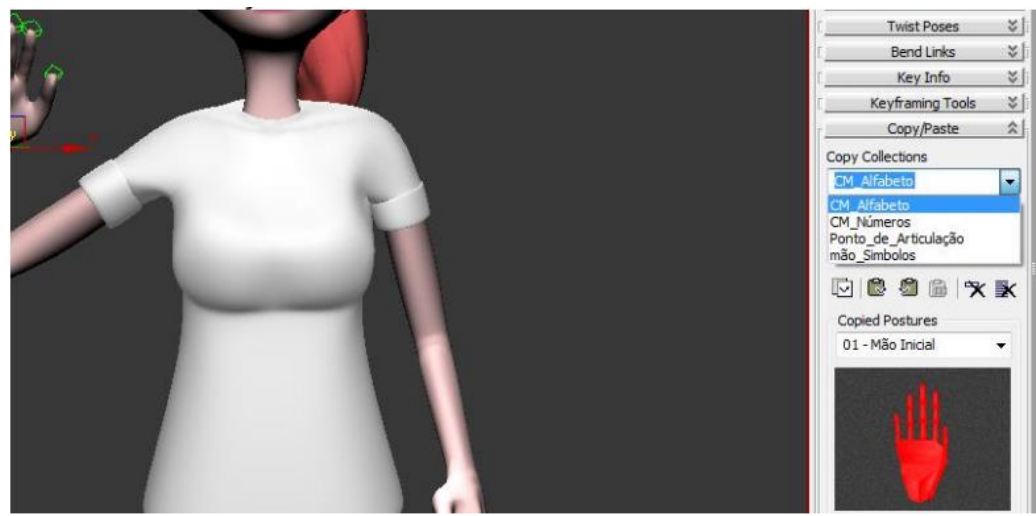

Figura 9: Caixa de Coleções

4. Após escolher a coleção, selecionamos qual a configuração de mão que será utilizada, no caso escolhemos a letra "O" como exemplo observado na Figura 10. Quando escolhemos uma configuração, é mostrada uma visualização da mão esquelética, clicamos no botão "Paste" para a mão direita e "Paste Oposite" para a mão esquerda, assim o personagem grava a configuração. Com isso fechamos mais um parâmetro, que é a configuração das mãos. 


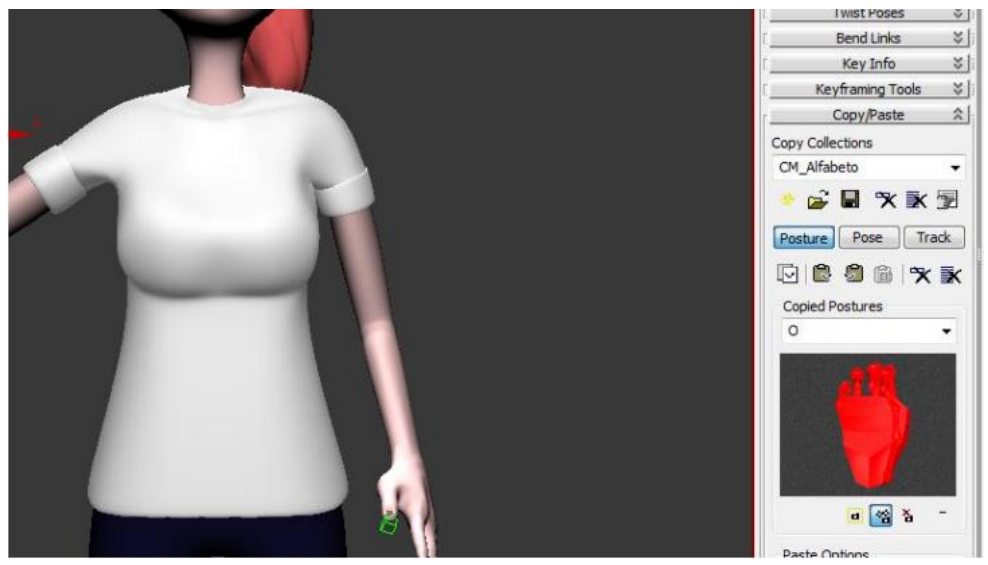

Figura 10: Caixa de Seleção de Configuração da Mão

5. Ainda nas coleções podemos escolher o ponto de articulação. Temos os seguintes pontos prédefinidos: PA_Abaixo_Cintura, PA_Acima_Cabeça, PA_Cintura, PA_Neutro, PA_Frente_à_Boca, PA_Frente_à_Testa, PA_Inicial, PA_Peito.
Depois de escolhido o ponto de articulação, no nosso caso "PA_Frente_à_Testa", clica-se também no botão Paste, visto na Figura 11.

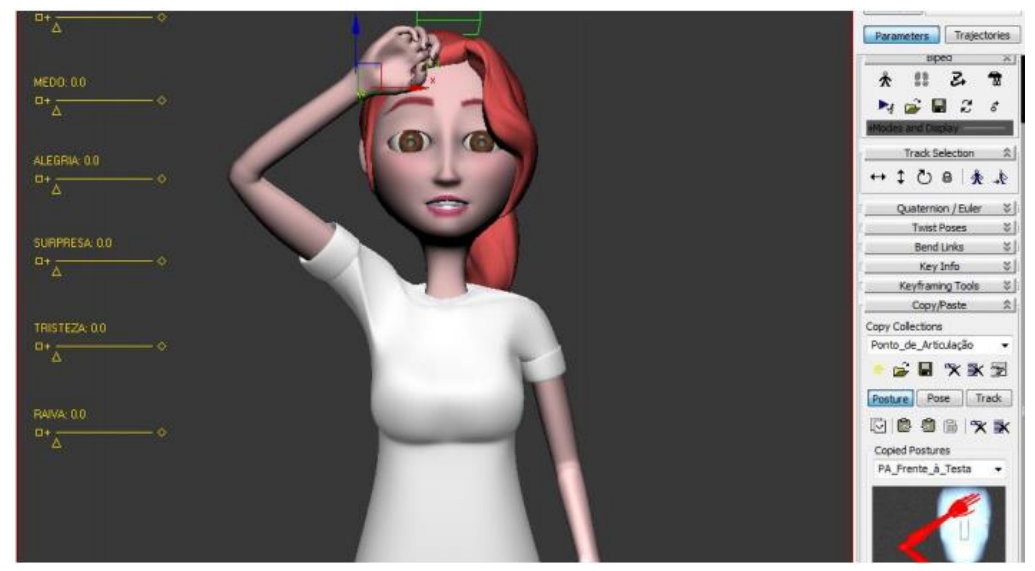

Figura 11: Ponto de Articulação

6. E por fim, temos a ferramenta mais interessante e didática do AssistLIBRAS, os manipuladores de expressão facial. Do lado do nosso personagem temos uma lista de manipuladores, onde os estados afetivos foram parametrizados em ordem numérica, ou seja, em uma escala de 0 a 100, quantificamos a intensidade da emoção, como visto na Figura 12. Com isso fechamos o último dos cinco parâmetros da língua de sinais, a expressão facial/corporal. 

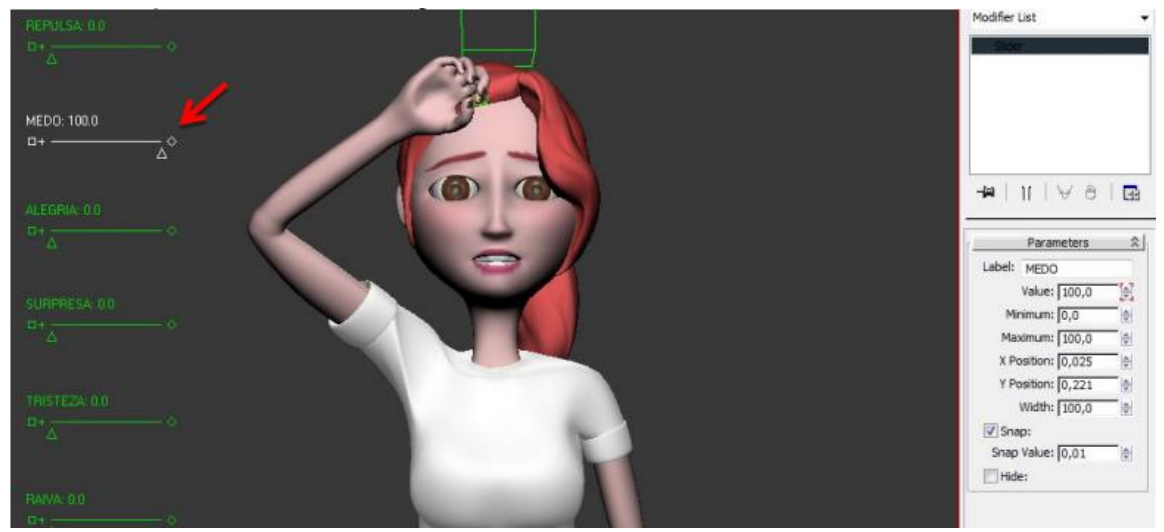

Figura 12: Manipuladores de Emoção

Seguindo o padrão apresentado em [11], as expressões dos personagens Sophya e Joe foram construídas de forma a serem o mais fieis possível garantindo o entendimento correto das emoções por parte do surdo, como observado nas Figuras 13 e 14.

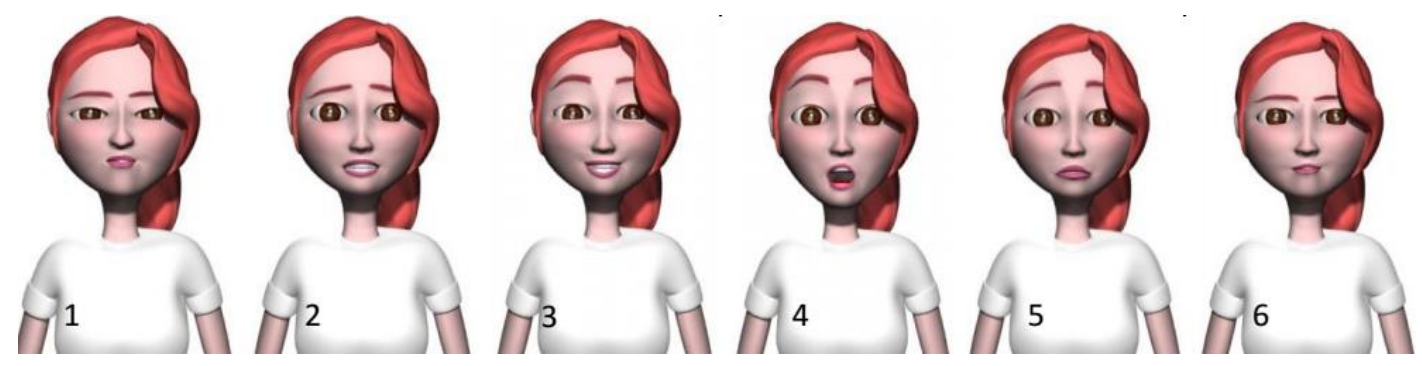

Figura 13: Expressões da personagem Sophya segundo o padrão em [11]
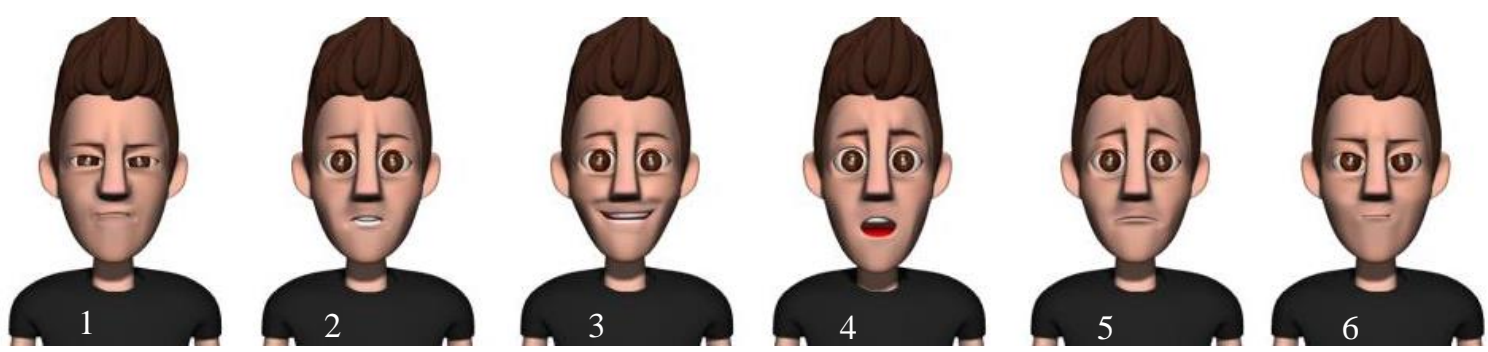

Figura 14: Expressões do personagem Joe segundo o padrão em [11] 
Pode-se perceber a importância de uma interface projetada para usuários leigos em animação gráfica, e até mesmo na língua de sinais, pois o usuário pode ser um intérprete da língua, como também um usuário "curioso" que através de um guia, como o website do INES (Instituto Nacional da Educação do Surdo), pode observar o sinal e reproduzi-lo com fidelidade.

Como visto, o que caracteriza o AssistLIBRAS como ferramenta de autoria são as suas pré configurações, que simbolizam os cinco parâmetros da LIBRAS. Diferentemente de ferramentas de animação tradicional, que fazem todo o processo de animação movendo "osso por osso" e "vértice por vértice", tendo um alto custo de produção com relação ao tempo de geração de sinais e demanda de mão de obra especializada, ou seja, profissionais de animação gráfica.

\section{Avaliação}

Nesta discutiremos a avaliação da ferramenta proposta, através de um caso de uso realizado com usuários de diferentes perfis: uma professora da Língua Brasileira de Sinais; um usuário leigo em computação gráfica e língua de sinais; e um aluno surdo.

Os resultados do caso de uso serão mostrados em forma de gráficos comentados.

\subsection{Com professora de LIBRAS}

O caso de uso proposto ao usuário (professora de LIBRAS) foi a criação de quatro sinais, onde estes seriam avaliados com relação a dois fatores: Tempo gasto em cada sinal; e Qualidade do sinal.

O conceito de pontuação admitido para demonstrar o fator "qualidade" está descrito logo abaixo, na tabela 1:

\begin{tabular}{l|l|l|l|l}
\hline Ruim & Regular & Bom & Ótimo & Excelente \\
\hline $\mathbf{2}$ & 4 & 6 & 8 & 10 \\
\hline
\end{tabular}

Tabela 1: Pontuação atribuída ao experimento

Tais resultados foram atribuídos por análise quantitativa e qualitativa do autor da ferramenta juntamente ao usuário em questão.

Depois de um breve treinamento com a professora de LIBRAS, a mesma foi capaz de gerar quatro sinais, onde nos gráficos a seguir percebemos a progressão da qualidade dos sinais gerados em relação ao tempo gasto. Podemos observar logo abaixo, no gráfico 1.

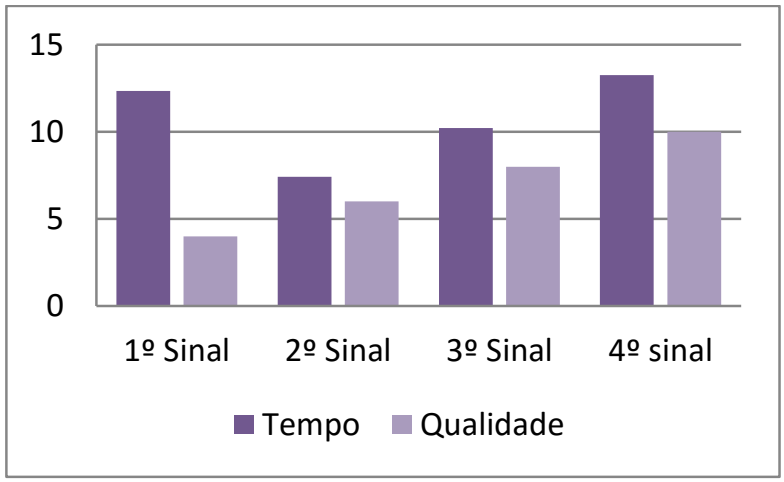

Gráfico 1: Geração de sinais pela professora de LIBRAS

Na geração do primeiro sinal, a palavra "falar", a professora gastou 12 minutos e 35 segundos, enquanto que a qualidade do sinal foi de apenas 4 pontos, sendo classificado como "regular", ou seja, a professora ainda estava se familiarizando com a ferramenta.

Já no segundo sinal, a palavra "gostar", percebemos que a mesma ganhou mais habilidade, pois diminuiu o tempo gasto para 7 minutos e 43 segundos, e a qualidade subiu para a nota 6 , dito como "bom".

O terceiro sinal criado foi a palavra "querer", onde a professora se prendeu mais a qualidade do sinal, deixando o tempo maior, com 10 minutos e 21 segundos, sendo o conceito de qualidade 8 , considerado como "ótimo".

O quarto e último sinal gerado foi o próprio nome da professora soletrado. Neste a professora se prendeu a qualidade e não se importou com o tempo gasto na animação, ou seja, o tempo foi de 13 minutos e 24 segundos, enquanto que a qualidade do sinal foi para 10 , o conceito máximo: "excelente”.

Pode-se perceber aqui que com a prática da usabilidade da ferramenta, as habilidades do usuário tendem a aumentar de forma linear, e o tempo gasto com cada animação é relativo a complexidade do sinal e ao cuidado do usuário em seguir com fidelidade o sinal a ser criado. Também podemos observar que pelo fato de a professora já ser conhecedora da língua, o tempo foi bastante otimizado, restando como limitações apenas a familiaridade com o conceito e práticas de animação gráfica.

\subsection{Com usuário leigo}


Nesta parte do caso de uso, também foram produzidos quatro sinais dentro do AssistLIBRAS, como visto no gráfico 2, onde o usuário utilizou o site do INES (Instituto Nacional de Educação do Surdo) como guia para a confecção dos mesmos.

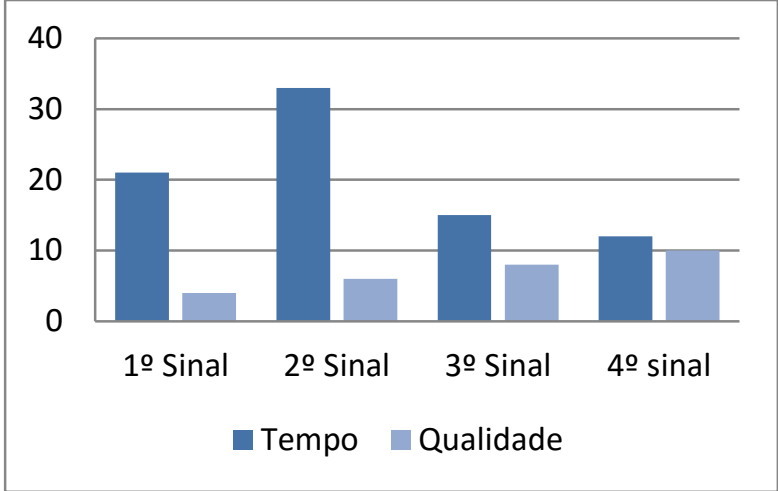

Gráfico 2: Geração de sinais por usuário leigo

O primeiro sinal produzido foi a palavra "correr". Como primeiro teste, o usuário demonstrou dificuldade com a ferramenta, por não conhecer estar habituado a um software 3D, e ainda estar aprendendo a manusear a interface, gastou 21 minutos e a qualidade foi regular, ou seja, o valor 4 mostrado no gráfico.

No segundo sinal, o usuário demorou mais tempo, 33 minutos, porém o mesmo prezou pela qualidade do sinal, que foi "bom", ou seja, valor 6 demonstrado no gráfico 2 . A palavra/expressão confeccionada foi "jogar futebol".

O terceiro sinal gerado foi através da palavra "sexo", onde o usuário demonstrou grande evolução, tanto no tempo quanto na qualidade, pois gastou somente $15 \mathrm{mi}-$ nutos e a qualidade do sinal foi ótima, ou seja, valor 8 do gráfico.

No último sinal, foi soletrado o nome do usuário. Neste teste o usuário demonstrou grande familiaridade com a ferramenta, tendo como valores: tempo: 12 minutos e qualidade: 10 .

Ao final dos testes, pode-se perceber que o usuário leigo, assim como a professora de LIBRAS, tiveram um crescimento na usabilidade da ferramenta em escala ascendente em termo de qualidade, mostrado também que o tempo gasto está intimamente ligado a dificuldade/facilidade do sinal, e qualidade esperada.

\subsection{Com o surdo:}

A parte do caso de uso referente ao usuário surdo foi a avaliação de alguns sinais dentro de um determinado contexto.

Tal experiência foi realizada em seu ambiente escolar, num computador, onde o mesmo possuía um tradutor, com os sinais produzidos no assistente gráfico.

Após a demonstração dos sinais através das orações traduzidas, o surdo deu sua avaliação respondendo a duas questões: Qual foi o nível de compreensão das frases? Tendo algumas opções objetivas descritas na tabela 2:

\begin{tabular}{l|l|l|l|l}
\hline A & B & C & D & E \\
\hline Ruim & Regular Bom Ótimo Excelente \\
\hline \multicolumn{4}{c}{ Tabela 2: Avaliação da Ferramenta }
\end{tabular}

O mesmo respondeu a alternativa “c)", já que o usuário não dominava completamente a língua de sinais, não conhecendo todas as palavras apresentadas no tradutor.

A segunda questão foi referente ao nível de satisfação na utilização do tradutor, onde numa escala de 0 a 10 , o mesmo assegurou satisfação total, ou seja, nota 10, devido à facilidade de manuseio da ferramenta e compreensão do que lhe era proposto.

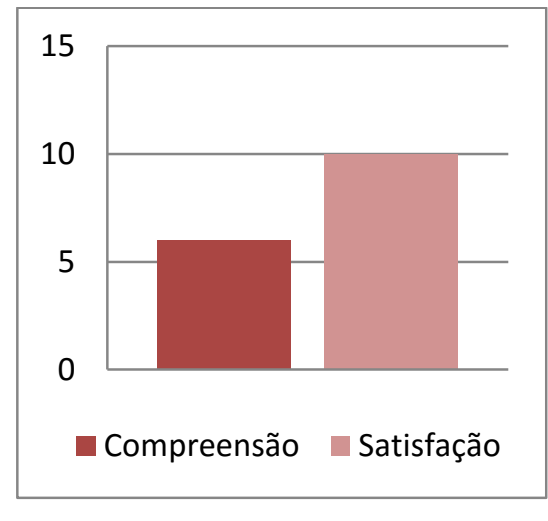

Gráfico 3: Avaliação do Surdo

Desta forma, percebeu-se que os sinais produzidos no assistente tiveram uma boa aceitação por parte do usuário final. Estes sinais foram testados através do tradutor FALIBRAS, mas podem ser incorporados a quaisquer tradutores ou dicionários.

\section{Trabalhos relacionados}


Existem alguns projetos semelhantes ao AssistLIBRAS, como é o caso do TLIBRAS [20], uma proposta de Tradutor Português-LIBRAS do Órgão Acessibilidade Brasil. Como descrito em sua home page: "Esse projeto está focado na construção de um tradutor automatizado de Português x LIBRAS, que possa ser utilizado em sala de aula, pela televisão (concomitante ou em substituição aos textos legendados), em vídeos, pela internet, na construção de livros visuais, traduzindo informações em português de origem textual ou sonora para LIBRAS, por meio de sinais animados e apresentados via computador."

Uma especificação do projeto TLIBRAS é o projeto de Computação Gráfica do mesmo, onde é produzido uma engine que renderiza em tempo real os sinais da LIBRAS representados por animações de um avatar 3D. Os movimentos nele produzidos se mostram ainda robóticos, e sem um importante fator para a compreensão do sinal: a expressão facial.

O Projeto Rybená [21], criado pelo Grupo ICTS (Instituto Centro de Pesquisa e Desenvolvimento em Tecnologia de Software), consiste em um tradutor em forma de player, que funciona em seu site.

A empresa Prodeaf [22] também é uma empresa do ramo de Acessibilidade direcionado ao Surdo Brasileiro. Nasceu como projeto na Universidade Federal de Pernambuco, possui foco em negócios, ou seja, algumas aplicações de tradutor e dicionário disponíveis no mercado para grandes organizações. Assim como o Hand Talk [23], desenvolvido por uma equipe alagoana, que tem o mesmo objetivo das demais.

Numa visão global temos a ferramenta WebSign [24] [25], que provê um ambiente para a construção de cursos online para surdos, onde o mesmo disponibiliza um banco de exercícios e utiliza um avatar com sinais e traduções prontas.

Todas essas tecnologias são aplicações finais, ou seja, se apresenta ao surdo como um produto final que passou pelas fases de criação do avatar, dos sinais através de animações, engine de tradução, e interface de usuário.

O AssistLIBRAS é uma ferramenta que contempla somente a fase de criação de sinais de LIBRAS. Porém o mesmo se diferencia das demais no processo que este se propõe a fazer, ou seja, a construção dos sinais é semiautomática e abstrai detalhes técnicos de animação, permitindo com que o especialista de domínio da língua gere seus próprios sinais. O que é diferente das ferramentas acima citadas, pois há dependência do profissional de animação gráfica para reproduzir o conhecimento do especialista de domínio.
Outra importante diferença entre os softwares acima citados e a ferramenta proposta neste artigo é o custo da geração dos sinais, que no AssistLIBRAS é bastante reduzido, pois otimiza vários passos através da disponibilização de um template com configurações pré prontas e reusáveis. Esse fator implica que, por as outras tecnologias aqui apontadas criarem animações da maneira tradicional precisando do profissional de animação, estas não são consideradas como ferramentas de autoria, mas sim como tecnologias assistivas direcionadas ao surdo, exceto [24] [25], que se caracteriza como ferramenta de autoria com relação a criação de cursos online para surdos.

\section{Considerações Finais}

Este trabalho teve caráter investigativo, pois para o correto entendimento do problema, foi feito um estudo do atual estado da arte sobre o surdo, língua de sinais, e tecnologias assistivas existentes, além de uma entrevista com o usuário avaliador da solução, o aluno surdo que reportou suas frustrações em sala de aula.

Percebemos que o problema da falta de acessibilidade para pessoas com necessidades especiais está longe de ser resolvido com apenas um software ou ferramenta.

Com a finalização da pesquisa, testes e análise dos resultados, pode-se perceber que o cenário das tecnologias assistivas é bastante novo e carente de novas soluções que atendam as reais necessidades de seus usuários.

Espera-se que esta ferramenta produzida possa ser utilizada em diversos contextos, com o intuito de realmente gerar mudança, sair do cenário acadêmico em direção à sociedade. E que este seja um incentivo para a criação de novas soluções direcionadas a pessoas que tem necessidades reais.

\section{Trabalhos Futuros}

Como trabalhos futuros, deseja-se criar uma versão online da ferramenta AssistLIBRAS, disponibilizando-a como meio construtor de um grande acervo de sinais padronizado, validado e aceito por toda a comunidade surda brasileira.

Uma limitação atual da ferramenta é referente ao conjunto de expressões faciais, pois a mesma possui somente as "marcações não-manuais afetivas", referentes às expressões de emoção. Dessa forma, como um trabalho futuro, é construir as "marcações não-manuais gramaticais", que configura um conjunto de expressões não relacionados à emoção, porém bastante utilizados em diversos sinais da língua.

Percebemos que outras línguas de sinais possuem seus parâmetros bastante similares, portanto o AssitLibras 
pode ser implementado com a gramática de qualquer língua de sinais, tendo uma nova conotação, como assistente de língua de sinais, independente qual seja a língua.

Outro objetivo futuro é tornar o assistente ainda mais próximo da realidade do usuário, deixando com que o mesmo possa personalizar de forma intuitiva o personagem proposto.

\section{Referências}

[1] M. P. Radabaugh. Study on the Financing of Assistive Technology Devices of Services for Individuals with Disabilities - A report to the president and the congress of the United State, National Council on Disability, Março 1993.

[2] Brasil. 23,9\% da população tinha pelo menos um dos tipos de deficiências investigados. Censo IBGE 2010. http://www.ibge.gov.br/home/presidencia/noticia s/noticia_visualiza.php?id_noticia=2125\&id_pag ina $=1$, Dez 2014.

[3] Brasil. Casa Civil da Presidência da República. LEI No 10.436, DE 24 DE ABRIL DE 2002.

http://www.planalto.gov.br/ccivil_03/leis/2002/L 10436.htm. Dez 2014

[4] E. M. A. Frias, M. C. B. Menezes. Inclusão Escolar do Aluno com Necessidades Educacionais Especiais: contribuições ao professor do Ensino Regular. http://www.diaadiaeducacao.pr.gov.br/portals/pd e/arquivos/1462-8.pdf. Dez 2014.

[5] F. C. Capovilla, W. D. Raphael. Dicionário Enciclopédico Ilustrado Trilíngue: Língua de Sinais Brasileira. 2. Ed. São Paulo: Edusp, 2001. p. 1632.

[6] A. M. V. Filho, P. C. Souza, J. B. M. Alves, R. S. Wazlawick, R. P. Luz. Ferramentas de Autoria de Realidade Virtual - um estudo comparativo. VI Congreso Internacional de Ingeniería Informática, 2000, Buenos Aires.

[7] V. J. Leffa. Uma ferramenta de autoria para o professor: o que é e o que faz. Letras de Hoje, Porto Alegre, v. 41, n. 144, p. 189-214, 2006.

[8] Brasil. Casa Civil da Presidência da República. DECRETO $\mathrm{N}^{\circ}$ 5.626, DE 22 DE DEZEMBRO DE 2005. Capítulo II, Artigo $3^{\circ}$. http://www.planalto.gov.br/ccivil_03/_ato20042006/2005/decreto/d5626.htm. Dez 2014.
Surdos e Pais Ouvintes. Livros Brasil. http://www.livrosbrasil.com.br/det_artigosoutros .asp?id_artigos=30, Dez 2014.

[10] P. A. Jaques, R. M. Viccari. Estado da arte em ambientes inteligentes de aprendizagem que consideram a afetividade do aluno. Revista Informática na Educação: Teoria \& Prática, v. 8, n. 1, p. 15-38, 2005a.

[11] P. Ekman, P. Facial Expressions. In: T. Dalgleish, , T. Power. (Ed.). The Handbook of Cognition and Emotion. Sussex, Reino Unido: John Wiley \& Sons Ltd: [s.n.], 1999. p.301-320.

[12] K. L. Schmidt, J. F. Cohn. Human facial expressions as adaptations: Evolutionary questions in facial expression. American Journal of Physical Anthropology (Yearbook of Physical Anthropology), v. 44, n. S33, p. 3-24, 2001.

[13] M. R. Stumpf. Transcrições de Língua de Sinais Brasileira em signwriting. In: Letramento e minorias/ Organizadores: Lodi, Ana Cláudia B, p.62.

[14] L. S. Vales. Pequeno Dicionário Regional de LIBRAS para Artes. Universidade Federal do Rio Grande do Sul. Faculdade de Educação. p. 27.2008. http://www.lume.ufrgs.br/bitstream/handle/1018 3/15665/000687612.pdf?sequence=1, Dez 2014.

[15] N. R. L. Sá. Cultura, poder e educação de surdos. 2. Ed. São Paulo: Paulinas, 2006, p. 113.

[16] M. Haghshenas, M. Khademi, H. Kabir. ELEARNING AND AUTHORING TOOLS : At a Glance. International journal of research and reviews in applied sciences. February 2012.

[17] J. Oliveira et al. Learning Management Systems \& Authoring Tools (State-of-the-Art). Corporate Software Engineering Knowledge Networks for Improved Training of the Work Force. Fraunhofer Institute for Experimental Software Engineering (IESE). Project of the Information Societies Technology (IST) Programme of the European Union March 2001, p. 82.

[18] Autodesk. Software de modelagem, animação e renderização em 3D. Disponível em http://www.autodesk.com.br/products/3dsmax/overview, Dez 2014.

[19] B. O. Schneider, L. P. Nedel. Simulação de Humanos Virtuais. 2006. http://www.inf.furb.br/gcg/projetos_pub/RAS/2RevisaoBibliografica.pdf. Dez 2014. 
[20] G. A. Lira. Projeto TLIBRAS - Tradutor Português x LIBRAS (Língua Brasileira de Sinais). Acessibilidade Brasil. http://www.acessobrasil.org.br/index.php?itemid =39, Dez 2014.

[21] ICTS. Projeto Rybená. http://www.grupoicts.com.br/. Dez 2014.

[22] PRODEAF. Soluções. http://www.prodeaf.net/, Dez 2014.

[23] Hand Talk. http://www.handtalk.com.br/, Dez 2014.

[24] Jemni, Mohamed, Oussama Elghoul, and Sana Makhlouf. "A web-based tool to create online courses for deaf pupils." International conference on interactive mobile and computer aided learning, Amman, Jordan. 2007.

[25] El Ghoul, Oussama, and Mohamed Jemni. "Multimedia courses generator for deaf children." Int. Arab J. Inf. Technol. 6.5 (2009): 457-462. 